\title{
NAV Inflation and Impact on Performance in China*
}

\author{
Mark Shackleton ${ }^{\dagger}$, Jiali Yan ${ }^{\ddagger}$, Yaqiong Yao ${ }^{\S}$
}

November 2018

\begin{abstract}
Our study is among the first to examine the net asset value (NAV) inflation practices of fund managers in China, finding that equity funds bolster their portfolios at quarter-end and especially year-end. In support of the NAV inflation hypothesis in China, we further document the following: (1) NAV inflation is more profound for the worst-performing fund managers and (2) the stocks in which fund managers hold larger stakes exhibit a more marked pattern of price inflation around quarter- and year-ends than do other stocks. We also find that closed-end funds in China engage in NAV inflation at quarter- and year-ends.
\end{abstract}

JEL classification: G11; G12; G23

Keywords: Mutual funds, NAV inflation, Chinese market, closed-end funds

\footnotetext{
* We thank John A. Doukas (the editor), an associate editor, and two anonymous referees for their comments, which significantly improved the paper. Our gratitude extends to Stephen Brown, Bing Han, William Pouliot, Russ Wermers, and the participants at the 2016 Portsmouth-Fordham Conference on Banking \& Finance, the IFABS Asia 2017 Ningbo China Conference, and the INFINITI Conference in International Finance 2017 for their useful comments. We especially thank Jiaguo (George) Wang for intensive discussions. Part of the paper was completed while Yaqiong Yao was visiting New York University's Stern School of Business in the spring of 2015 and Shanghai University of International Business and Economics in September 2015 and December 2017 and to Jeanne Bovenberg for excellent editorial assistance.

$\dagger$ Department of Accounting and Finance, Lancaster University Management School, Lancaster, LA1 4YX, United Kingdom. Email m.shackleton@lancaster.ac.uk; tel. +44 1524594131.

* Department of Accounting and Finance, Lancaster University Management School, Lancaster, LA1 4YX, United Kingdom. Email j.yan@lancaster.ac.uk; tel. +44 7922485780.

$\S$ Department of Accounting and Finance, Lancaster University Management School, Lancaster, LA1 4YX, United Kingdom. Email yaqiong.yao@lancaster.ac.uk; tel. +44 1524510731.
} 


\section{Introduction}

Previous studies have highlighted a potential agency problem in the mutual fund industry: managers could manipulate quarter- and year-end stock prices by excessively purchasing stocks they already hold to bolster fund performance. This practice is commonly referred to as net asset value (NAV) inflation, marking up, or "tape painting." The financial press, rating institutions and regulators pay disproportionately high attention to funds' quarterly and annual performance, which could link to the practice of NAV inflation at quarter- and year-end. Fund managers could aggressively buy stocks in their portfolios, effectively "borrowing" from future performance to push up current returns. Consequently, funds have abnormally high returns at quarter-ends, followed by return reversals at the beginning of the subsequent months.

This trading behavior could have detrimental impacts on the two fundamental aspects of financial markets: market liquidity and pricing accuracy (Kyle \& Viswanathan, 2008). There has been mounting evidence of NAV inflation trades of mutual funds in the United States (Carhart, Kaniel, Musto, \& Reed, 2002). Subsequent studies provide supportive evidence for hedge funds in the United States (Agarwal, Daniel, \& Naik, 2011) and for mutual funds in Australia (Gallagher, Gardner, \& Swan, 2009). Most of the studies focus on developed markets but ignore one of the most important emerging countries, China, which has the second largest stock market in the world.

Compared with those well-developed markets, the Chinese market has a short history and contends with incomplete regulation, opaque information disclosure, and weak legal enforcement. ${ }^{1}$ The institutional environment is relatively underdeveloped in both the Chinese financial markets and external corporate governance mechanisms, since shareholder activism is nearly nonexistent (Jiang, Rao, \& Yue, 2014). Meanwhile, the legal protection of minority shareholders is especially weak (Allen, Qian, \& Qian, 2005). Compared with the US Securities and Exchange Commission (SEC), the China Securities Regulatory Commission (CSRC) is weak in terms of impacting policy, focusing instead on

\footnotetext{
${ }^{1}$ See Cheung, Jing, Lu, Rau, and Stouraitis (2009), Cheung, Rau, and Stouraitis (2009), Chi (2016), and Gao, Yan, Yang, and Zhao (2016).
} 
maintaining the stability of national economic growth. ${ }^{2}$ It is critical to understand the behavior of fund managers in China and potential impacts on fund performance. Naturally, this makes the Chinese market an ideal testing ground for comparing NAV inflation behavior in an emerging and fast-growing market to that in developed markets. How different in this respect, if at all, is China from developed markets?

Our study is among the first to examine NAV inflation behavior in China and to explore its potential impact on fund performance in the Chinese mutual fund market. We find that fund managers in China inflate their end-of-quarter and particularly end-of-year NAVs to boost their returns in the current period, leading to return reversals at the turn of the quarter. Further, the analysis shows that, on average, fund returns are much higher during the final two trading days at quarter-end than they are during the first two trading days of the following quarter, especially for the fourth quarter (i.e., yearend). In China, a fund's year-based performance draws high attention from the media, rating institutions, and scholars. Managers' annual compensation packages are partially determined by their ranking among their peers at the end of the calendar year. ${ }^{3}$ It is possible that such year-end ranking incentives lead to especially strong NAV inflation at year-end.

Using the market as a benchmark, we find that the adjusted NAVs of the value-weighted (VW) portfolio are marked up by an average of 23 basis points at quarter-end, a markup that is considerably larger than that documented in the US market (Carhart et al., 2002) and half the magnitude documented in the Australian market (Gallagher et al., 2009). We further show that these patterns are not driven by exposure to common factors. Specifically, we investigate the behavior of funds by examining their benchmark-adjusted returns based on Carhart's (1997) four-factor model. We find that the NAV inflation effect remains statistically and economically significant.

Further, we examine whether fund managers who have greater incentives to mark up their performance are more involved in NAV inflation practices than their less incentivized counterparts are. We investigate this question through two channels. The first is related to the convex relation between

\footnotetext{
${ }^{2}$ See the report by Citi Securities and Fund Services in 2012, at http://www.citibank.com/transactionservices/ home/about_us/articles/docs/china_asset.pdf.

${ }^{3}$ See the popular fund-ranking website in China http://cn.morningstar.com/main/default.aspx.
} 
past performance and future flows. ${ }^{4}$ That is, investors make purchase decisions based on a fund's prior performance, but could do so asymmetrically, investing disproportionately more in funds that performed very well in the prior period. Therefore, managers of high-performing funds have strong incentives to pump up their returns to attract more flows. The second channel is related to the inverse relation between the probability of managerial replacement and a fund's past performance (Khorana, 1996). Given this inverse relation, fund managers under threat of being replaced increase portfolio turnover. For instance, poor performers could tend to pump up their existing holdings to decrease the probability of dismissal.

Prior studies suggest that, in the US markets, funds with the best past performance are more actively involved in quarter-end trades (Carhart et al., 2002; Duong \& Meschke, 2016). By contrast, in the Australian market, poor performers display more evidence of portfolio pumping (Gallagher et al., 2009). We find that the Chinese market resembles the Australian market more, with poorly performing funds, rather than higher-performing funds, engaging in NAV inflation practices. The results could be driven by differences between Chinese and U.S. mutual funds, where the former are less sensitive to performance ranking than the latter. Jun, Li, Yan \& Zhang (2014) find that receiving a five-star Morningstar rating does not seem to significantly impact a fund's future flows. The authors also document that high-performing Chinese mutual funds in one period do not attract more fund flows in the next period. ${ }^{5}$ By contrast, the convex relation between performance and flow is found in the United States (Chevalier \& Ellison, 1997; Gruber, 1996; Ippolito, 1992; Sirri \& Tufano, 1998).

Our study contributes to the literature that studies fund performance on the basis of disclosed fund portfolio holdings (Huang, Sialm, \& Zhang, 2011; Kacperczyk, Sialm, \& Zheng, 2008; Wermers, 2000). Taking advantage of the holding information in Chinese mutual fund filings, we find that the equities in which Chinese active equity funds hold larger stakes show more price inflation around quarter- and year-end than do others. This finding thus supports the notion that Chinese fund managers are involved in NAV inflation through excessive end-of-quarter and end-of-year stock purchasing.

\footnotetext{
${ }^{4}$ See Chevalier and Ellison (1997), Gruber (1996), Ippolito (1992), Phillips, Pukthuanthong, and Rau (2017) and Sirri and Tufano (1998).

${ }^{5}$ Insert a footnote here
} 
Having extended our analyses to closed-end funds, we find that the NAV inflation pattern around quarter- and year-ends also exists for closed-end funds in China. Bhattacharyya and Nanda (2012) discuss the pricing of closed-end funds, arguing that NAV inflation should exist among them. To the best of our knowledge, we are among the first not only to provide new empirical support for this prediction but also to examine NAV inflation in closed-end funds.

The paper proceeds as follows. Section 2 discusses the related literature on NAV inflation. Section 3 describes the sample and presents summary statistics. Section 4 develops empirical predictions. Section 5 analyzes the empirical results of NAV inflation. Section 6 concludes the paper.

\section{Related literature}

Various newspaper articles have reported on the practice of NAV inflation in the United States (Hansard, 2000; Hill, 2000; Zweig, 1997; Zweig \& McGinty, 2012). Zweig and McGinty (2012) suggest that a considerable number of stocks outperform the market—namely, the Standard \& Poor's (S\&P) 500 stock index — on the final trading day of each quarter but therefore underperform it on the following trading day. The authors claim that NAV inflation can explain this abnormal pattern. They also indicate that it is difficult for regulators to detect fund managers' NAV inflation activities without the availability of detailed trading records.

Carhart et al. (2002) were among the first to analyze the NAV inflation of US equity funds. Using a sample period between 1985 and 1997, they find that fund returns, net of S\&P 500 portfolio returns, are considerably larger on the final trading day of a quarter and then reverse the following day. Moreover, the authors find that these patterns of return reversal are strongest for the best-performing funds. Having considered the work of Carhart et al. (2002) as a quasi-exogenous shock to regulatory scrutiny, Duong and Meschke (2016) find that NAV inflation has substantially weakened since the SEC filed a fraud indictment against fund managers who were involved in NAV inflation in $2001 .{ }^{6}$ During

\footnotetext{
${ }^{6}$ On June 1, 2001, the SEC filed securities fraud charges against a fund manager of Friedlander International Limited for being involved in portfolio pumping. On August 10, 2001, the SEC instituted and settled administrative proceedings against ABN-AMRO Incomplete., Oechsle International Advisor LLC, and two of 
their sample period from 1993 to 2006, they document that both winner and loser funds pumped their portfolios intensely at the turns of the quarter.

Prior studies have also documented that hedge funds are involved in NAV inflation. Agarwal et al. (2011) argue that, compared with mutual fund managers, hedge fund managers are prone to manipulate year-end performance because of their incentive fee compensation structures. The authors show that hedge fund returns display a spike in December. Having examined the holding data of hedge funds, Ben-David, Franzoni, Landier, and Moussawi (2013) find that the pumping behavior of fund managers can significantly distort in stock prices. Using transaction-level trading data, Hu, McLean, Pontiff, and Wang (2014) provide confirmatory evidence of NAV inflation among US institutional investors.

Apart from a growing body of empirical literature that studies the impact of NAV inflation on fund performance, recent theoretical studies justify the existence of NAV inflation trading and predict the consequences. Bhattacharyya and Nanda (2012) develop an equilibrium model in which a fund manager's remuneration is based on the NAV of their funds. They argue that a fund manager's concern with short-term fund performance always provides enough incentive for them to manipulate the closing price. Their model also predicts that NAV inflation can lead to decreasing returns to scale because of related transaction costs. Bernhardt and Davies (2009) reveal that the price inflation caused by pumping trades near quarter-end is interim; thus, a return shortfall can occur in the first trading session of the following quarter.

Less attention has been paid by researchers, regulators, and the media to Chinese fund managers' NAV inflation. To address this gap, this study attempts to examine the evidence of this misbehavior in China's mutual fund industry, an environment that has been less effective and competitive than the United States. For example, the penetration of mutual funds in China is much lower than that of the United States: the ratio of assets under management (AUM) to the gross domestic product is only $11 \%$ in China, far lower than $91 \%$ in the United States. In Western countries such as the

their managers for engaging in portfolio pumping (see www.sec.gov/litigation/litreleases/lr17021.htm, ww.sec.gov/litigation/admin/ia-1966.htm, and www.sec.gov/litigation/admin/34-44679.htm). 
United States, mutual funds are regarded as investment tools, saving tools, and retirement plans. By contrast, in Asian countries such as China, investors treat mutual funds mainly as a trading tool. ${ }^{7}$

\section{Data and summary statistics}

\subsection{Data}

We obtain mutual fund data from the China Stock Market \& Accounting Research (CSMAR) database, including NAVs, distribution, and total net assets (TNA). We define active mutual funds using objective $\operatorname{codes}^{8}$ and the composition of a fund's total assets. We eliminate exchange-traded funds, qualified domestic institutional investor funds and index tracking funds. We exclude mutual funds that, on average, hold less than $80 \%$ of their total assets in equities (see also Huang et al., 2011; Kacperczyk et al., 2008). ${ }^{9}$ To lessen the influence of new funds with insufficient return histories, we use only funds that appear in the CSMAR database more than one year before the end of our sample period. ${ }^{10}$ The final selection criterion reduces the maximum number of mutual funds in our study to 276 . Our sample period covers January 2, 2004, to December 31, 2013.

\footnotetext{
7 See the report of Asian mutual funds by Ernst \& Young LLP in 2016, http://www.ey.com/Publication/ vwLUAssets/ey-mutual-funds-ready-for-the-next-leap/\$FILE/ey-mutual-funds-ready-for-the-next-leap.pdf.

${ }^{8}$ We select mutual funds that have the following objective codes in the CSMAR fund database: Fund Type ID S0501 and Category ID IsETF $=2$, IsQDII $=2$, and IsIndexFund $=2$.

${ }^{9}$ It is worth mentioning that our mutual fund data could suffer less from three kinds of biases that often occur in US mutual fund databases. The first is the backfill bias that is often associated with incubator funds (Evans, 2010). Incubation is a process via which a fund family provides several funds with seed money to develop a return history. At the end of the incubator period, the best-performing fund will be made public and will be included in the databases with a favorable return history, whereas unsuccessful incubated funds will be closed or merged, their past returns never being recorded in databases. This approach leads to an upward bias in mutual fund returns. Such incubation bias may not arise in our database, however, because all Chinese mutual funds must make public reports about their establishment to the CSRC. The second bias relates to the incompleteness of data for small funds (Elton, Gruber, \& Blake, 2001). In the United States, funds with under $\$ 15$ million in assets do not need to report their NAVs daily. If they survive, they will be recorded in the database with their return history; otherwise, they may never appear in the database. However, at the inception, the size of a fund will not be extremely small in China. The third bias is the survivorship bias in mutual fund databases (Brown, Goetzmann, Ibbotson, \& Ross 1992). For instance, when using the January 2013 Morningstar database to download 10 years of returns, funds that existed in 2003 but did not survive until 2013 were excluded. This resulted in obvious biases in the first and second moments and cross-moments of the return. As previously shown in Table 1, all open-end funds in the CSMAR database were still alive at the end of our sample periods.

${ }^{10}$ For a robustness check, we added back those funds with less than a year's history to our sample, with the findings still holding. Then, because the CSRC defines an equity fund as a mutual fund that invests at least $60 \%$ of its total assets in stocks during our sample period, we relax our criteria of a fund investing $80 \%$ in the stock markets to $60 \%$. The $60 \%$ threshold allows for a larger sample, with up to 459 funds at the end of 2013 . Our results remain robust to these changes. The results are available upon request.
} 
Equity funds in China invest mainly in Chinese A-shares ${ }^{11}$ listed on the Shanghai Stock Exchange (SHSE) and Shenzhen Stock Exchange (SZSE). ${ }^{12}$ We obtain stock data from the CSMAR databases, including the daily market returns of A-shares listed in the SHSE and SZSE, daily stock returns, total share numbers, total market values, and the book value of total shareholder equity. We use the one-year fixed-term deposit rate set by the Chinese government as a proxy for the return risk-free rate obtained from the CSMAR. ${ }^{13}$ To match the sample period of our mutual fund study, our stock market data also span the period from January 2, 2004, to December 31, 2013.

\subsection{Summary statistics}

Table 1 shows that, during our sample period, the number of active equity funds increased from 13 in 2004 to 276 in 2013. Total AUM increased from 25 billion yuan in 2004 to 1.052 trillion yuan in 2007 , followed by a decrease to 774 billion yuan. The VW gross return on the portfolio of active funds reached a peak of $106.26 \%$ per annum in 2006, with a lowest return of $-55.68 \%$ per annum in 2008 . This mirrors the Chinese stock market, which experienced a dramatic uptrend in 2006 followed by a sharp drop in 2008. The volatile performance of active funds reflects China's turbulent stock market.

[Insert Table 1 here]

Table 2 shows returns to the VW and EW portfolios of active funds, as well as their characteristics. Our sample includes up to 276 distinct funds and 333,194 daily fund observations from January 2, 2004, to December 31, 2013. Panels A and B respectively report the monthly and daily net and gross returns of the VW and EW actively managed equity mutual fund portfolios. On average, the monthly VW gross return (0.96\%) is slightly higher than the corresponding EW gross return $(0.74 \%)$. This finding implies that large funds outperform small funds in China. In sharp contrast, prior studies

\footnotetext{
${ }^{11}$ We include stocks listed in both the Small Medium Enterprise Board and the Growth Enterprise Board, hosted by the SZSE.

${ }^{12}$ A-shares are only available to domestic Chinese investors and are denominated in RMB, while B-shares are only available to foreign investors and are denominated in Hong Kong dollars on the SZSE and in US dollars on the SHSE. Nevertheless, in 2001, B-shares were available to domestic investors who had foreign currency accounts.

${ }^{13}$ The Ministry of Finance in China usually issues bonds that have terms longer than three years and the supply of short-period bonds in China is lower than in the United States.
} 
document that small funds outperform large funds in the US market (e.g., Chen, Hong, Huang, \& Kubik, 2004).

Panel B of Table 2 reports the average age, TNA, expense ratio, cash, and stock positions of the portfolio of active funds in China. The average age is 4.59 years, which is significantly lower than the average age of US funds (16.08 years according to Huang et al., 2011), while the average annual expense ratio for equity funds is $2.84 \%$ per annum, considerably higher than the average of $1 \%$ in the US market (French, 2010). Average TNA is 4.56 billion yuan during the sample period of 2004 to 2013 , which is lower than the average TNA of US equity funds ( $\$ 1.182$ billion during the sample period of 1998 to 2008). The average cash proportion is $9.29 \%$, while the average stock proportion is $84.07 \% .^{14}$ By compaararison, US active equity funds invest more in stocks (92.67\%) and less in cash (5.60\%) (Huang et al., 2011). The rest is invested in bonds and other securities.

\section{[Insert Table 2 here]}

\subsection{Common factors}

To measure fund performance, we construct value, size, and momentum factors (Carhart, 1997; Fama \& French, 1993) based on Chinese stock market characteristics. At the end of June of each year $t$, the SHSE and SZSE A-shares are sorted into two size groups based on the total market value of all of the tradable A-shares on these exchanges. Then, within each size group, stocks are allocated to three book-to-price $(B / P)$ ratio equity groups: growth (i.e., bottom $30 \%$ ), medium (i.e., middle $40 \%$ ), and value (i.e., top $30 \%$ ). The $B / P$ ratio in year $t$ is defined as the book value of equity per share in year $t-1$, divided by the end-of-year closing price in year $t-1$. The reason for not using the book-to-market ratio - as Fama and French (1993) do - is that Chinese listed companies usually issue multiple class shares. Since these shares have the same cash flow and voting rights, they have a similar claim on the book value of a company's shareholder equity. To lower the influence of multiple shares, we calculate

\footnotetext{
${ }^{14}$ In our sample, in certain months, 10 equity funds have a stock ratio of less than $50 \%$. Note that the stock ratio will be more than $60 \%$ in the second disclosure after their inception date.
} 
the $B / P$ ratio as the book value of shareholder equity per $\mathrm{A}$-share divided by the $\mathrm{A}$-share price $(\mathrm{Xu} \&$ Zhang, 2014).

The intersection of the size and value sorts creates six VW portfolios $(S / L, S / M, S / H, B / L, B / M$, and $B / H$ ), which are updated each June. The momentum factor is constructed similarly to the value factor, except that we sort on past returns instead of the $B / P$ ratio and the momentum factor sort is updated monthly instead of annually. At the end of each month $t-1$, stocks are sorted into three momentum portfolios (up, medium, and down) based on the 30th and 70th percentiles of the past 11 months' cumulative returns to the end of month $t-2$. The intersection of the size sort for the most recent June and the momentum sort creates six VW portfolios, which are updated monthly.

The market factor is calculated as the VW returns of tradable A-shares minus the risk-free rate. The market value of tradable A-shares at the end of day $t$ - 1 is used to calculate VW daily returns (with cash dividends reinvested on day $t$ ). The size factor, SMB, is the difference between the average of returns on the three small stock portfolios $(S / L, S / M$, and $S / H)$ and the average of returns on the three big stock portfolios $(B / L, B / M$, and $B / H)$. The value factor, HML, is the difference between the average of returns on the two value portfolios $(S / H$ and $B / H)$ and that on the two growth portfolios $(S / L$ and $B / L)$. The momentum factor, UMD, is the simple average of returns on the two up momentum portfolios minus that on the two down momentum portfolios.

Table 3 presents summary statistics for the returns of the market, value, size, and momentum factors from 2004 to 2013 . The average monthly return of the market factor is the highest, at $1.24 \%$ per month $(t$-value $=1.46)$. The average monthly return of the size factor is $0.864 \%$ per $(t$-value $=2.01)$, which suggests a size premium in the Chinese stock market (Xu \& Zhang, 2004). The average daily returns of the value and momentum factors are small and insignificant $(0.14 \%, t$-value $=0.50$, and $0.12 \%, t$-value $=0.35$, respectively)

[Insert Table 3 here] 


\subsection{Risk-adjusted returns}

We compute the VW and EW returns of the portfolio of active domestic equity funds, where the returns are weighted by the fund's AUM at the end of the prior month. We calculate the daily market-adjusted returns $\left(R_{m f, t}-R_{m k t, t}\right)$ as the daily net returns of the fund portfolio minus the daily VW returns of the Chinese stock market, including all of the tradable A-shares listed on the SHSE and SZSE. We also use Carhart's (1997) four-factor model to evaluate funds: ${ }^{15}$

$R_{i, t}-R_{f, t}=a_{i}+b_{i}\left(R_{m k t, t}-R_{f, t}\right)+s_{i} S M B_{t}+h_{i} H M L_{t}+m_{i} U M D_{t}+e_{i, t}$,

where the dependent variable $R_{i, t}-R_{f, t}$ is the return on fund $i$ for day $t$ minus the risk-free rate (the one-year fixed-term deposit rate) and the independent variables are the returns on the market, size, value, and momentum portfolios. The excess market return is $R_{m k t, t}-R_{f, t}$ (the return on a VW market portfolio of tradable A-shares in the SHSE and SZSE minus the risk-free rate); $S M B_{t}, H M L_{t}$ and $U M D_{t}$ are the Chinese versions of the size, value, and momentum factors of Carhart (1997) and Fama and French (1993). The average return $a_{i}$ is left unexplained by those factor models and $e_{i, t}$ is the residual.

\section{Hypothesis development}

The inflation of NAV is a typical agency problem between fund managers and investors. Fund managers are concerned about the fund's TNA because their compensation is usually a fixed proportion of it (Bhattacharyya \& Nanda, 2012). Thus, managers might want to manipulate fund performance to attract more fund flows and enlarge their fee base and remain employed. ${ }^{16}$ The performance-flow relation indeed serves as an implicit incentive contract for fund managers (Chevalier \& Ellison, 1997). However, as equity claimants of a mutual fund, investors always expect value-maximizing decisions from fund managers (Fama \& Jensen, 1985) and holders are more concerned with fund returns than

\footnotetext{
${ }^{15}$ In untabulated analysis, we also measure fund performance by abnormal returns calculated from the capital asset pricing model of Lintner (1965) and Sharpe (1964) and from the Fama-French (1993) three-factor model. The results, quantitatively similar, are available upon request.

${ }^{16}$ Kane, Santini, and Aber (1991), Lakonishok, Shleifer, and Vishny (1992), Smith (1978), and Spitz (1970) find a positive performance-flow relation.
} 
fund flows. The separation of interests and the information asymmetry between the two parties therefore leads to an agency conflict. Since fund investors cannot observe the exact timing of trades and consequent transaction costs, they must bear the corresponding agency costs (Kacperczyk et al., 2008).

Previous studies examine NAV inflation by detecting fund return reversal patterns around quarter-ends. If fund managers mark up their portfolios, fund returns are expected to be abnormally high at quarter-end and abnormally low at the beginning of the subsequent quarter. First, Bhattacharyya and Nanda (2012) predict that the excessive trading volume along with NAV inflation boosts a mutual fund's short-run performance at the expense of long-run performance because of incurring costs. Fund managers' NAV inflation incentives also result in decreasing returns to scale in the presence of transaction costs. Second, Bernhardt and Davies (2009) document that excessive NAV inflation at the period end has a short-term price impact; each following period thus starts with a return deficit. This leads to the following hypothesis.

H1: The pumping behavior of equity fund managers inflates their NAVs, which results in earning abnormally high returns toward the quarter- and year-end, followed by abnormally low returns the following quarter and the start of the next year.

Carhart et al. (2002) hypothesize that the best performers in the past year have more incentives to inflate their NAVs; the authors find that these top-performing funds do pump up their stocks very aggressively, given the convex relation between past performance and future flows. ${ }^{17}$ Mutual fund investors usually reward funds for stellar performance with higher flows but do not reduce flows proportionally to underperformance. Therefore, the best-performing funds can exploit profits from further rank improvements through NAV inflation, especially because they know that they are unlikely to be top-performing funds the following year. ${ }^{18}$

In contrast to the managers of the best-performing funds, the managers of the worst-performing funds are faced with the threat of dismissal due to the inverse relation between the probability of

\footnotetext{
${ }^{17}$ For the nonlinear fund performance-flow relation, please also refer to Chevalier and Ellison (1997), Goetzmann and Peles (1997), Gruber (1996), Ippolito (1992) and Sirri and Tufano (1998).

${ }^{18}$ See also Brown and Goetzmann (1995), Carhart (1997), Goetzmann and Ibbotson (1994) and Hendricks, Patel, and Zeckhauser (1993) for documentary evidence of short-term persistence in mutual fund performance.
} 
managerial replacement and past fund performance (Khorana, 1996). In the presence of this replacement-performance relation, underperforming fund managers are more likely to engage in NAV inflation at each quarter-end to increase the perceived fund performance. The incentive behind this behavior is consistent with that of selling funds that increase the risk toward year-end (Brown, Harlow, \& Starks, 1996). Moreover, Bhattacharyya and Nanda (2012) show that the volume of pumping trades increases with the level of concern regarding short-term performance. Compared with other managers, the worst-performing fund managers are more likely to engage in NAV inflation because of magnified career concerns at the end of an evaluation period. Thus, we propose the following hypothesis.

H2: Compared with median-performing equity funds, the best- and worst-performing equity funds are pumped up more at quarter-and year-end.

\section{Results}

\subsection{Market-adjusted performance at the turn of quarters}

This section tests whether those mutual funds that are involved in quarter-end (and especially year-end) NAV inflation consequently experience deteriorating performance at the beginning of the subsequent quarter. If NAVs are inflated at quarter- and year-end, we should expect abnormally high returns around the quarter-end and abnormally low returns around the beginning of the subsequent period. We show direct evidence of return reversal patterns around quarter-end that are consistent with the NAV inflation hypothesis.

Table 4 reports the market-adjusted returns of the portfolio of active domestic equity funds around the turn of each quarter-end. We calculate the market-adjusted returns as the daily net returns of the portfolio of equity funds minus the daily market return. In Panels A and B, Ret End is the average of the funds' market-adjusted returns on the final two trading days of each quarter and Ret Beginning is the average of the market-adjusted returns on the first two trading days of the subsequent quarter; Ret Difference is the difference between Ret Beginning and Ret End at the turn of each quarter.

Table 4 shows that, on average, the market-adjusted return of the VW (EW) fund portfolio is 14.21 basis points ( 16.70 basis points) at the quarter-end and becomes -18.17 basis points $(-18.93$ basis 
points) at the beginning of the following quarters; the overall effect is thus negative. The fourth quarter shows the strongest reversal pattern. Over only two working days around the year-end, the drop in market-adjusted returns is $-71.55(-65.45)$ for the $\mathrm{VW}(\mathrm{EW})$ fund portfolio at the $1 \%$ level of significance. ${ }^{19}$ We then test whether those mutual funds that are involved in quarter-end (and especially year-end) NAV inflation consequently experience deteriorating performance at the beginning of the next quarter period. If NAVs are inflated at quarter- or year-end, we expect abnormally high returns around the end of the period and abnormally low returns around the beginning of the subsequent period.

[Insert Table 4 here]

\subsection{Model-based performance at the turn of quarters}

\subsubsection{Across quarters}

Next, we use the Carhart (1997) four-factor model to evaluate the fund's portfolio performance. Let $X_{m f, t}$ denote the daily market-adjusted returns and the Carhart (1997) model-based daily abnormal returns of the VW and EW portfolios of equity funds on day $t$ (where $t$ is from January 2, 2004, to December 31, 2013). We run the following ordinary least squares indicator variable regression:

$$
X_{m f, t}=a_{0}+a_{1} Y E N D_{t}+a_{2} Y B E G_{t}+a_{3} Q E N D_{t}+a_{4} Q B E G_{t}+a_{5} M E N D_{t}+a_{6} M B E G_{t}+\varepsilon_{m f, t},
$$

where $Y E N D_{t}$ is one if $t$ is the final two trading days of December; $Y B E G_{t}$ is one if $t$ is the first two trading days of January; $Q E N D_{t}$ is one if $t$ is the final two trading days of March, June, or September; $Q B E G_{t}$ is one if $t$ is the first two trading days of April, July, or October; $M E N D_{t}$ is one if $t$ is the final two trading days of any other month but not the last day of a quarter; and $M B E G_{t}$ is one if $t$ is the first two trading days of any other month but not the first day of a quarter.

The results are summarized in Table 5. Panel A reports the NAV inflation effect based on the two-day window around period ends. We find strong NAV inflation effects at quarter- and year-end,

\footnotetext{
${ }^{19}$ We find that the VW and EW fund portfolio results are quantitatively similar. For brevity, we do not tabulate the EW fund portfolio results, which are available upon request.
} 
but no such effect in other months. Of the four coefficients on $Y E N D_{t}$ and $Q E N D_{t}$ in Panel A, all are in the predicted direction and statistically significant at the $10 \%$ level. This evidence supports our hypothesis that equity fund managers manage NAV inflation at quarter-end, leading to abnormally high returns. The price impact of NAV inflation is considerable; for example, the market-adjusted returns at quarter-end add up to 91.40 basis points per year, which is much higher than the returns documented in the US equity fund market (Carhart et al., 2002).

\section{[Insert Table 5 Here]}

With the mutual fund industry in China still in its early stages of development, there is a great need for relevant laws and regulations to be further developed and legal enforcement strengthened. Information disclosure is not comprehensive. For example, fund managers in China do not describe their investment styles, provide information on fees, or report transaction costs clearly in their prospectuses. All of these elements make it easier for a fund manager to pump up his or her portfolio among peer groups in China.

In China, the media, rating institutions, and scholars pay sharp attention to a fund's year-based performance. Fund managers are evaluated and rewarded through a ranking mechanism, with their compensation packages being partially dependent on their ranking among peer competitors at the end of the calendar year. Performance rankings at year-end are potential drivers of portfolio pumping, as evidenced by the quarter-end rise and next-day decline, especially pronounced at year-end.

Regarding the beginning of each quarter and year, there are no significantly positive coefficients. Since excessive NAV inflation trades give rise to higher transaction costs, fund managers mark up short-term performance at the expense of future returns. Along with the temporary effect of inflation trades, low returns at the start of the quarter are consistent with our prediction as well. In addition, NAV inflation effects around the remaining month-end are weak. All four coefficients on $M E N D_{t}$ and $M B E G_{t}$ are relatively small in absolute values and none are statistically significant, indicating that end-of-month effects are not present.

Panel B of Table 5 enlarges our test window of NAV inflation from two days (before/after) to five days (before/after). We find that the NAV inflation effect almost disappears during the five-day 
window; for example, the coefficients on $Y E N D_{t}$ are not significant, regardless of whether we use market-adjusted returns or abnormal returns. This evidence is consistent with the theoretical prediction of Bernhardt and Davis (2009). They argue that the price impact of NAV inflation trades at quarterends arises only in the short term, since short-run performance will decrease with subsequent cash inflows, which leads to lower long-run performance. Empirically, Brown, Sotes-Paladino, Wang, and Yao (2017) and Carhart et al. (2002) find NAV inflation in the US fund market through one- and twoday window tests, respectively. Thus, if we expand our test window to a longer period, the NAV inflation effect will disappear accordingly.

\subsubsection{At each quarter}

To differentiate the NAV inflation effect at each quarter, we expand our model in Table 6 and regress the dependent variable $X_{m f, t}$ on 10 dummy variables to test quarter-end seasonality:

$$
\begin{gathered}
X_{m f, t}=a_{0}+a_{1} Y E N D_{t}+a_{2} Y B E G_{t}+a_{3} Q_{1} E N D_{t}+a_{4} Q_{1} B E G_{t}+a_{5} Q_{2} E N D_{t}+a_{6} Q_{2} B E G_{t}+ \\
a_{7} Q_{3} E N D_{t}+a_{8} Q_{3} B E G_{t}+a_{9} M E N D_{t}+a_{10} M B E G_{t}+\varepsilon_{m f, t},
\end{gathered}
$$

where $Y E N D_{t}$ is one if $t$ is the final two trading days of December; $Y B E G_{t}$ is one if $t$ is the first two trading days of January; $Q_{1} E N D_{t}$ is one if $t$ is the final two trading days of March; $Q_{1} B E G_{t}$ is one if $t$ is the first two trading days of April; $Q_{2} E N D_{t}$ is one if $t$ is the final two trading days of June; $Q_{2} B E G_{t}$ is one if $t$ is the first two trading days of July; $Q_{3} E N D_{t}$ is one if $t$ is the final two trading days of September; $Q_{3} B E G_{t}$ is one if $t$ is the first two trading days of October; $M E N D_{t}$ is one if $t$ is the final two trading days of any other month but not the last day of a quarter; and $M B E G_{t}$ is one if $t$ is the first two trading days of any other month but not the first trading day of a quarter.

To see the average quarter-end NAV inflation effect, we also report the regression results of All - QEND (the average of $Y E N D_{t}, Q_{1} E N D_{t}, Q_{2} E N D_{t}$ and $Q_{3} E N D_{t}$ ), which are the final two trading days of each quarter, and $A l l-Q B E G$ (the average of $Y B E G_{t}, Q_{1} B E G_{t}, Q_{2} B E G_{t}$, and $Q_{3} B E G_{t}$ ), which are the first two trading days of each quarter. We report the coefficients in Panel 
A $(Y E N D / Y B E G)$, Panel B (Q1END/Q1BEG), Panel C (Q2END/Q2BEG), Panel D (Q3END/ Q3BEG), Panel E (All - QEND)/(ALL - QBEG), and Panel F (MEND /MBEG) of Table 6.

[Insert Table 6 here]

Our results show that fund managers are inclined to pump up fund portfolios at the end of the second, third, and especially fourth quarter rather than the first quarter. For the two-day window results, all the coefficients on YEND are positive and significant at the 5\% level; the model-based fund abnormal returns are significant and positive for Q3END. Moreover, the coefficients on $Q 2 E N D$ are positive and significant at the 5\% level when the dependent variables are the market-adjusted fund returns. In contrast, none of the coefficients on $Q 1 E N D$ are significant. On average, the quarter-end market-adjusted performance of fund portfolios is abnormally high: it is equivalent to 23 basis points per two days for the fund portfolio. The findings provide further evidence of NAV inflation trades (particularly at year-end) and strong subsequent return reversal patterns at the beginning of the year. We also expand our study window to five days around the end of each period and find that the NAV inflation effect barely exists, supporting the hypothesis that the price impact of NAV inflation is temporary, which is consistent with the work of Bernhardt and Davis (2009), Brown et al. (2017), and Carhart et al. (2002). We thus opt to use the two-day window in our remaining tests.

\subsection{How the best and worst performers perform at the turn of quarters}

The previous section provided evidence of NAV inflation in the Chinese markets. This section takes a step further to examine subgroups of equity funds, namely, the best- and worst-performing funds. On the one hand, the best-performing fund managers are likely to inflate the prices of stocks held in their portfolios to benefit from the convex performance-flow relation (Ippolito, 1992; Sirri \& Tufano, 1998). In other words, those managers who are in a tournament can profit more from improving their ranking. On the other hand, the worst-performing fund managers face the possibility of dismissal at period end; they will therefore also be inclined to pump up to improve fund performance due to career concerns. 
For each working day $t$ from January 4, 2005, to December 31, 2013, we sort all equity funds into quintile portfolios based on their cumulative return over the prior 243 trading days, ending day $t-$ $2 .{ }^{20}$ Funds with the worst performance the prior year are assigned to the first quintile portfolio (the loser portfolio, P1), funds with median performance are assigned to the third quintile portfolio (the medium portfolio, P3), and the funds with the highest performance are assigned to the fifth quintile portfolio (the winner portfolio, P5). The difference test between P5 (P1) and P3 entails examining the return differences between the winner (loser) portfolio and the medium group, which is calculated as the return of the winner (loser) portfolio less the return of the median performance portfolio.

We run daily market-adjusted returns and abnormal returns for the mutual fund portfolio, as well as the return differences on the quarter- and year-end indicator variables using equation (4). The results are presented in Table 7. The coefficients are arranged into panels: YEND/YBEG in Panel A, QEND/QBEG in Panel B, and MEND/MBEG in Panel C.

\section{[Insert Table 7 here]}

Among the quintile portfolios, the loser fund portfolio shows considerable quarter- and yearend NAV inflation. There is a strong return reversal pattern for both the market-adjusted returns and the model-based abnormal returns of the loser portfolio at the turn of the year in Panel A, with abnormal returns (losses) amounting to 19 basis points (-17 basis points). In addition, the coefficients on QEND in Panel B are positive and significant at the $1 \%$ level for the loser portfolios. Moreover, the difference test of the YEND and QEND coefficients between P1 and P3 suggests that the loser portfolio earns around 16 basis points ( 16 basis points) greater abnormal returns than the median performance portfolio at the year-end (quarter-end). The findings suggest that, compared with medium-performing fund managers, the worst-performing fund managers are actively involved in NAV inflation at quarter- and year-end in the Chinese market. Gallagher et al. (2009) document that, in the Australian market, poor performers display greater evidence of NAV inflation practices. Similar to the Australian evidence, our

${ }^{20}$ In China, the average number of trading days per year is 243 . 
evidence suggests that the worst performers, rather than the best performers, are involved in buying their existing positions and pumping up prices.

By comparison, more than half of the $Y E N D$ and $Q E N D$ coefficients from the difference test between P5 and P3 are insignificant. The economic magnitude is also slightly lower: the winner funds show about eight basis points (10 basis points) more abnormal returns than the median performance funds at year-end (quarter-end). The findings provide little evidence of the best-performing fund managers engaging in NAV inflation trades, which is inconsistent with the US evidence (Carhart et al., 2002; Duong \& Meschke, 2016). Prior studies of the US market document that, due to the convex relation between performance and flow, fund managers have stronger incentives to pump up the existing holdings of the best performers. Our analysis implies that flows in China are less sensitive to performance ranking than their US counterparts seem to be. This difference could be due to the fact that the increasing numbers of funds available every year in the United States dilute flows away from those best performers, whereas the opposite is true in China: the expansion of the fund industry cannot keep pace with the substantial increases in flows. ${ }^{21}$

\subsection{Holding-based analysis}

This section conducts a holding-based analysis, an approach that is widely used in empirical research to measure mutual fund performance (Huang et al., 2011; Kacperczyk et al., 2008; Wermers, 2000). NAV inflation activities indicate that equities in which mutual funds own substantial stakes should be more subject to the inflation effect around quarter- and year-end (Hu et al., 2014). Thus, we take advantage of the semiannual filings of important stock holdings of Chinese mutual funds from the CSMAR database to examine the stock price inflation pattern around period ends. ${ }^{22}$ In June and December of each year, we rank all the stocks (based on their ownership ratio) held by Chinese active

21 One might wonder about whether the worst-performing funds (P1) would benefit more if only the bestperforming funds (P5) pumped up the stocks that they hold, since they do not bear the cost of pumping. If those non-pumpers absorbed the positive externality from the behavior of pumpers, then we should observe the middle quintile portfolios (i.e., P2, P3, and P4) having as strong a NAV inflation pattern as the worst-performing funds (P1). This is, however, not the case, which lessens this concern.

${ }_{22}$ More details about Chinese mutual fund disclosure requirements can be found in Appendix B. 
mutual funds into five quintiles. The institutional ownership ratio is calculated as the share price for each security times the number of shares held by mutual funds, divided by the security's total market value. For each quintile, we use stock market capitalization to form a VW portfolio. We run the following regression:

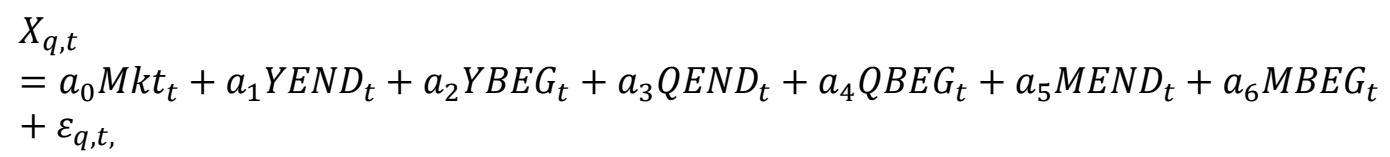

where indicators $Y E N D, Y B E G, Q E N D, Q B E G, M E N D$, and $M B E G$ are defined as in previous sections, $X_{q, t}$ is the VW average of these stock returns in quintile $q$, and $M k t_{t}$ represents the daily VW returns of the Chinese stock market, including all tradable A-shares listed in the SHSE and SZSE.

In Table 8, we find strong stock price inflation effects around quarter- and year-end for the bestperforming portfolio (P5) and almost no such effects in relatively low ownership portfolios. The coefficients on $Y E N D_{t}$ and $Q E N D_{t}$ are in the predicted direction and are statistically significant at the 5\% level. Moreover, we observe that NAV inflation effects around the remaining month-end are almost insignificant. This evidence of the price inflation of held stock further supports our previous findings on NAV inflation practices in the Chinese mutual fund industry; it also confirms that fund managers in China are involved in NAV inflation through the excessive purchases of stocks that they already hold, particularly those stocks in which they own large stakes.

Further, the holdings-based analysis can, to some extent, remove the concern that the abnormally high fund returns at quarter- and year-ends documented in this paper are consistent with reporting manipulation. Although reporting manipulation is illegal in China and fund managers are required by the CSRC to guarantee the truthfulness and correctness of the holdings disclosure, this possibility cannot be ruled out, given the fact that the Chinese fund markets are at such an early stage of development. If the inflation effects were evident mainly in reported fund returns (and not in the prices of the stocks held by the funds), then that would imply that our findings in Sections 5.1 and 5.2 are more consistent with reporting manipulation. The holdings-based analysis, however, provides 
evidence of price inflation of held stocks, which indicates that our findings may be driven more by portfolio pumping.

\section{[Insert Tables 8 here]}

\subsection{Closed-end fund analysis}

This section carries out the NAV inflation test for Chinese closed-end funds. Bhattacharyya and Nanda (2012) predict that portfolio pumping biases skew NAV measures upward and state that the logic of portfolio pumping should apply to closed-end funds as well. Although the number of Chinese closed-end funds is small (88), we are still interested in seeing what happens to then around quarterand year-ends. We obtain closed-end fund data from the CSMAR fund database and rerun model (2) for Chinese closed-end funds from the beginning of 2004 to the end of 2013. Table 9 reports that the closed-end fund portfolio shows substantial quarter- and year-end NAV inflation, with returns ranging from 5.38 basis points to 92.60 basis points. The magnitude of NAV inflation at quarter- and year-ends from the model-based abnormal returns for closed-end funds is similar to that for open-end funds in the previous section. Further, the presence of NAV inflation in closed-end funds indicates that the fund flow-performance relation might be a less important motivation for NAV inflation than previous studies have indicated.

\section{[Insert Table 9 here]}

\subsection{Summary}

Overall, our results support the hypothesis that the pumping behavior of Chinese fund managers inflates their NAVs, which leads to abnormally better performance toward quarters-ends and especially year-ends, which is followed by abnormally worse performance in the subsequent quarter and the beginning of the next year. In the meanwhile, this NAV behavior is more prevalent among the worst-performing fund managers. Additionally, the NAV inflation patterns found in the holding-based analysis and the closed-end fund analysis further strengthen our findings. 


\section{Conclusions}

Given the relatively less developed nature of regulation of the Chinese capital market compared to the US market, it is natural to expect Chinese fund managers to be actively involved in NAV inflation close to their performance evaluation periods. We provide strong evidence that Chinese actively managed domestic equity funds are pumped up at the quarter-ends, particularly at year-ends. Our findings remain robust to using both market-adjusted and model-based abnormal performance measures. Specifically, we find that fund portfolios exhibit abnormally high end-of-quarter returns and a subsequent decrease at the start of the next quarter, which is consistent with NAV inflation behavior. We show that these patterns are stronger for the worst-performing funds, which could have greater incentives to avoid potential penalties. Our findings are further supported by fund holding tests and closed-end fund tests.

Our findings have several important implications for Chinese investors, policy makers, and regulators. Our study is among the first to empirically examine the NAV inflation behavior of mutual funds in the Chinese market. In the United States, the pivotal paper about NAV inflation by Carhart et al. (2002) caused the SEC to take regulatory action regarding this now-illegal behavior; since then, NAV inflation among US equity funds has decreased substantially (Duong \& Meschke, 2016). In contrast, researchers, regulators, and the press in China have paid little attention to fund managers' NAV inflation. Generally, NAV inflation distorts security prices from their natural levels and raises trading costs. Although the price distortions resulting from NAV inflation are short term around quarterends, their influence could be large, due to the prevalent use of NAV inflation across the Chinese mutual fund industry. It is thus important to design sophisticated methods to detect this behavior. Beyond the scope of this study, further research is warranted to look into the use of fund trading data to examine NAV inflation in China's mutual fund industry more directly. Trade data can be used to record and scrutinize fund managers' purchase or sale orders executed in the final trading session of each quarter (Gallagher et al., 2009).

The return reversal pattern that we document at the turns of quarters provides an appealing trading rule for Chinese fund investors. Since fund prices are inflated at the end of each quarter and fall 
back at the beginning of the following quarter, other investors can earn abnormal returns through selling (buying) fund shares at the last (first) trading session of each quarter. In particular, as the year draws to a close, fund investors who cash out can potentially make considerable profits at the expense of those who buy into mutual funds. However, given that actively managed mutual funds levy a redemption fee and impose restrictions on frequent trading, investors could find it difficult to exit from or enter into mutual funds flexibly. Thus, it is still uncertain whether they can exploit the effect of a fund manager's NAV inflation behavior.

Our findings also highlight the important role for Chinese financial regulators in improving the disclosure quality in the Chinese mutual fund industry through increasing the frequency of required complete disclosures. ${ }^{23}$ Broadly speaking, more frequent disclosure helps improve the liquidity and transparency of financial markets (Agarwal, Mullally, Tang, \& Yang, 2015). Specifically, more frequent disclosure requirements help fund investors and regulators to more effectively monitor fund management. Frank, Shackelford, and Shoven (2004) and Ge and Zheng (2006) find that more frequent disclosure enables fund investors and regulators to discover and punish any fund manager misbehavior. Therefore, we suggest that, in addition to the semiannual disclosure of full holdings, Chinese fund managers should be required to file their complete portfolio holdings with the CSRC in the quarterly report toward the end of both the first and third quarters of each year. However, the potential costs of frequent disclosure should also be considered; for instance, a fund's valuable research conclusions and private information could be used by its competitors as soon as the detailed portfolio compositions are disclosed. $^{24}$

Further, it would be interesting to examine whether funds with a non-Chinese clientele operating in China behave differently from the funds that are the focus of this study. This would help in disentangling manipulation reporting from portfolio pumping (since those funds may have less incentive to distort reporting). Due to the unavailability of data, we leave those important issues for future research. ${ }^{25}$

${ }^{23}$ We summarize the disclosure requirements of fund portfolio holdings in China in Appendix B.

${ }^{24}$ Various costs of frequent disclosure are discussed in detail by Wermers (2001).

${ }^{25}$ We thank an anonymous referee for suggesting this important dimension. 


\section{References}

Agarwal, V., Daniel, N., \& Naik, N. (2011). Do hedge funds manage their reported returns? Review of Financial Studies, 24, 3281-3320.

Agarwal, V., Mullally, K., Tang, Y., \& Yang, B. (2015). Mandatory portfolio disclosure, stock liquidity and mutual fund performance. Journal of Finance, 70, 2733-2776.

Allen, F., Qian, J., \& Qian, M. (2005). Law, finance and economic growth in China. Journal of Financial Economics, 77, 57-116.

Ben-David, I., Franzoni, F., Landier, A., \& Moussawi, R. (2013). Do hedge funds manipulate stock prices? Journal of Finance, 68, 2383-2434.

Bernhardt, D., \& Davies, R.J. (2009). Smart fund managers? Stupid money? Canadian Journal of Economics, 42, 719-748.

Bhattacharyya, S., \& Nanda, V. (2012). Portfolio pumping, trading activity and fund performance. Review of Finance, 17, 1-35.

Brown, K., Harlow, W., \& Starks, L. (1996). Of tournaments and temptations: An analysis of managerial incentives in the mutual fund industry. Journal of Finance, 51, 85-110.

Brown, S., \& Goetzmann, W. (1995). Performance persistence. Journal of Finance, 50, 679-698.

Brown, S., Goetzmann, W., Ibbotson, R., \& Ross, S. (1992). Survivorship bias in performance studies. Review of Financial Studies, 5, 553-580.

Brown, S., Sotes-Paladino, J.M., Wang, J., \& Yao, Y. (2017). Starting on the wrong foot: Seasonality in mutual fund performance. Journal of Banking and Finance, 82, 133-150.

Carhart, M. (1997). On persistence in mutual fund performance. Journal of Finance, 52, 57-82.

Carhart, M., Kaniel, R., Musto, D., \& Reed, A. (2002). Leaning for the tape: Evidence of gaming behavior in equity mutual funds. Journal of Finance, 5, 661-93.

Chen, J., Hong, H., Huang, M., \& Kubik, J.D. (2004). Does fund size erode mutual fund performance? The role of liquidity and organization. American Economic Review, 94, 1276-1302.

Cheung, Y., Jing, L., Lu, T., Rau, P.R., \& Stouraitis, A. (2009). Tunneling and propping up: An analysis of related party transactions by Chinese listed companies. Pacific-Basin Finance Journal, 17, 372-393.

Cheung, Y., Rau, P.R., \& Stouraitis, A. (2006). Tunneling, propping and expropriation: Evidence from connected party transactions in Hong Kong. Journal of Financial Economics, 82, 343-386. 
Chevalier, J., \& Ellison, G. (1997). Risk taking by mutual funds as a response to incentives. Journal of Political Economy, 105, 1167-1200.

Chi, Y. (2016). Private information in the Chinese stock market: Evidence from mutual funds and corporate insiders. Working paper, Chicago Booth School of Business.

Duong, T.X., \& Meschke, F. (2016). The rise and fall of portfolio pumping among U.S. mutual funds. Working paper, National University of Singapore.

Elton, E., Gruber, M., \& Blake, C. (2001). A first look at the accuracy of the CRSP mutual fund database and a comparison of the CRSP and Morningstar mutual fund databases. Journal of Finance, $56,2415-2450$.

Evans, R. (2010). Mutual fund incubation. Journal of Finance, 65, 1581-1611.

Fama, E., \& French, K. (1993). Common risk factors in the returns on stocks and bonds. Journal of Financial Economics, 33, 3-56.

Fama, E., \& Jensen, M. (1985). Organizational forms and investment decisions. Journal of Financial Economics, 14, 101-119.

Frank, M., Shackelford, D., \& Shoven, J. (2004). Copycat funds: Information disclosure regulation and the returns to active management in the mutual fund industry. Journal of Law and Economics, 47, 515-541.

French, K.R. (2008). Presidential address: The cost of active investing. The Journal of Finance, 63, 1537-1573.

Gallagher, D., Gardner, P., \& Swan, P.L. (2009). Portfolio pumping: An examination of investment manager quarter-end trading and impact on performance. Pacific-Basin Finance Journal, 17, 1-27.

Gao, H., Yan, H., Yang, X., \& Zhao, L. (2016). Does legal enforcement matter for financial risks? The case of strategic default in China. Working paper, Shanghai Jiaotong University.

Ge, W., \& Lu, Z. (2006). The frequency of mutual fund portfolio disclosure. Working paper, University of Washington and University of California, Irvine.

Goetzmann, W., \& Ibbotson, R. (1994). Do winners repeat? Journal of Portfolio Management, 20, 918.

Goetzmann, W., \& Peles, N. (1997). Cognitive dissonance and mutual fund investors. Journal of Financial Research, 20, 145-58.

Gruber, M. (1996). Another puzzle: The growth in actively managed mutual funds. Journal of Finance, 51, 783-810. 
Hansard, S. (2000). SEC set to adopt mutual fund name rule by year-end. Dow Jones Newswires, October 12.

Hendricks, D., Patel, J., \& Zeckhauser, R. (1993). Hot hands in mutual funds: Short-run persistence of relative performance 1974-1988. Journal of Finance, 48, 93-130.

Hill, M. (2000). Investors should be wary of last-day fund inflation. Knight Ridder Tribune Business News, January 4.

Hu, G., McLean, R., Pontiff, J., \& Wang, Q. (2014). The year-end trading activities of institutional investors: Evidence from daily trades. Review of Financial Studies, 27, 1593-1614.

Huang, J., Sialm, C., \& Zhang, H. (2011). Risk shifting and mutual fund performance. The Review of Financial Studies, 24, 2575-2616.

Ippolito, R. (1992). Consumer reaction to measures of poor quality: Evidence from the mutual fund industry. Journal of Law and Economics, 35, 45-70.

Jiang, G., Rao, P., \& Yue, H. (2015). Tunneling through non-operational fund occupancy: An investigation based on officially identified activities. Journal of Corporate Finance, 32, 295-311. Jun, Xiao, Li Mingsheng, Yan Wu, \& Zhang Rui (2014). Flow-performance relationship and star effect: New evidence from Chinese mutual funds. Emerging Markets Finance and Trade, 50, 81-101. Kacperczyk, M., Sialm, C., \& Zheng, L. (2008). Unobserved actions of mutual funds. Review of Financial Studies, 21, 2379-2416.

Kane, A., Santini, D., \& Aber, J. (1991). Lessons from the growth history of mutual funds. Working paper, University of California.

Khorana, A. (1996). Top management turnover, an empirical investigation of mutual fund managers. Journal of Financial Economics, 40, 403-427.

Kyle, A., \& Viswanathan, S. (2008). How to define illegal price manipulation. American Economic Review, 98, 274-279.

Lakonishok, J., Shleifer, A., \& Vishny, R. (1992). The structure and performance of the money management industry. Brookings Papers on Economic Activity, Microeconomics, 339-79.

Lintner, J. (1965). The valuation of risk assets and the selection of risky investments in stock portfolios and capital budgets. Review of Economics and Statistics, 13-37.

Phillips, B., Pukthuanthong, K., \& Rau, P.R. (2017). Past performance may be an illusion: Performance, flows and fees in mutual funds. Critical Finance Review, forthcoming. 
Sharpe, W.F. (1964). Capital asset prices: A theory of market equilibrium under conditions of risk. Journal of Finance, 19, 425-442.

Sirri, E., \& Tufano, P. (1998). Costly search and mutual fund flows. Journal of Finance, 52, 1589622.

Smith, K. (1978). Is fund growth related to fund performance? Journal of Portfolio Management, (Spring), 4, 49-54.

Spitz, A. (1970). Mutual fund performance and cash inflow. Applied Economics, 2, 141-45.

Wermers, R. (2000). Mutual fund performance: An empirical decomposition into stock-picking talent, style, transactions costs and expenses. Journal of Finance, 55, 1655-1695.

Wermers, R. (2001). The potential effects of more frequent portfolio disclosure on mutual fund performance. Investment Company Institute Perspective, 7, 1-11.

Xu, J., \& Zhang, S. (2014). The Fama-French three factors in the Chinese stock market. China Accounting and Finance Review, 16, 1-18.

Zweig, J. (1997). Watch out for the year-end flimflam. Money Magazine, November, 130-133.

Zweig, J., \& McGinty, T. (2012). Fund managers lift results with timely trading sprees. The Wall Street Journal, December 6. 
Table 1 Summary statistics by year

This table presents the numbers of active equity funds, equal-weighted (EW) and VW net and gross returns (in percent), and the TNA under management in the Chinese market each year from 2004 to 2013. Gross daily returns are calculated as daily net returns plus 1/244th of a fund's total annual expense ratio. Here TNA represent the average of yearly TNA under management, in billions of yuan. The sample includes active equity mutual funds that hold more than $80 \%$ in the domestic stock market and that were made public at least one year before the end of the sample period. Qualified domestic institutional investor funds, index funds, and exchange-traded funds are excluded.

\begin{tabular}{lrrrrrr}
\hline \multirow{2}{*}{ Year } & \multicolumn{5}{c}{ No. } & \multicolumn{2}{c}{ VW Return } & \multicolumn{2}{c}{ EW Return } & \multicolumn{1}{c}{$\begin{array}{c}\text { TNA } \\
\text { (bill yuan) }\end{array}$} \\
\cline { 3 - 6 } & & \multicolumn{1}{c}{ Gross } & \multicolumn{1}{c}{ Net } & \multicolumn{1}{c}{ Gross } & \multicolumn{1}{c}{ Net } & \\
\hline 2004 & 13 & -6.47 & -7.93 & 2.88 & 1.15 & 25 \\
2005 & 33 & 0.73 & -1.10 & 1.52 & -0.30 & 34 \\
2006 & 73 & 106.26 & 103.76 & 86.54 & 84.26 & 133 \\
2007 & 110 & 56.19 & 52.69 & 48.07 & 44.64 & 1052 \\
2008 & 134 & -55.68 & -57.53 & -53.75 & -55.71 & 867 \\
2009 & 175 & 68.54 & 65.05 & 63.52 & 59.74 & 942 \\
2010 & 208 & -3.57 & -5.97 & -1.13 & -3.87 & 959 \\
2011 & 245 & -25.77 & -27.89 & -25.70 & -28.04 & 835 \\
2012 & 276 & 4.66 & 2.30 & 4.98 & 2.17 & 738 \\
2013 & 276 & 11.16 & 8.43 & 14.27 & 10.83 & 774 \\
\hline
\end{tabular}


Table 2 Fund returns and characteristics

Table 2 reports the gross and net returns (in percent) of the portfolio of Chinese actively managed equity mutual funds. The monthly returns are presented in Panel A; the corresponding daily returns are summarized in Panel B. The daily gross returns are calculated as the daily net returns plus $1 / 244$ th of a fund's total annual expense ratio, while the monthly gross returns are calculated as the monthly net returns plus $1 / 12$ th of a fund's total annual expense ratio. Panel $\mathrm{C}$ reports the fund age, TNA, expense ratio, and stock proportion of the mutual fund portfolio. Here, TNA, reported in billions of yuan, is the TNA under management at the end of each quarter. The cash ratio is calculated as the cash held by a fund divided by the fund's total assets at the end of a year. The stock ratio is calculated as the market value of stocks held by a fund divided by the fund's total assets at the end of a year. The annual expense ratio is reported as a percentage. The sample includes 333,194 daily fund observations from January 2, 2004, to December 31, 2013.

\begin{tabular}{llllll}
\hline Variable & Mean & Std. Dev. & Min & Median & Max \\
\hline
\end{tabular}

Panel A: Monthly Returns (in percent)

\begin{tabular}{lllllll}
\hline \multirow{2}{*}{ VW } & Gross & 0.96 & 7.49 & -20.52 & 1.60 & 18.83 \\
& Net & 0.76 & 7.50 & -20.68 & 1.33 & 18.57 \\
EW & Gross & 0.74 & 6.98 & -20.56 & 1.51 & 15.99 \\
& Net & 0.53 & 6.98 & -20.73 & 1.22 & 15.75 \\
\hline
\end{tabular}

Panel B: Characteristics

\begin{tabular}{lrrrrr}
\hline Age (years) & 4.59 & 2.37 & 1.00 & 4.00 & 10.00 \\
TNA (billions of yuan) & 4.56 & 5.20 & 0.03 & 2.71 & 54.02 \\
Expense Ratio (percent per year) & 2.84 & 1.20 & 0.10 & 2.60 & 12.71 \\
Cash Ratio (percent) & 9.29 & 3.86 & 0.14 & 9.35 & 24.13 \\
Stock Proportion (percent) & 84.07 & 7.88 & 18.97 & 85.90 & 94.72 \\
\hline
\end{tabular}


Table 3 Summary statistics for the daily and monthly explanatory returns of the Fama-French three

factors and Carhart four factors in the Chinese stock markets

Panel A reports the Chinese daily time series averages of the cross-sectional summary statistics for each Carhart (1997) four-factor variable from January 2, 2004, to December 31, 2013. The variable $R_{m k t}$ is the return on a VW market portfolio of Chinese stock, including all tradable A-shares listed in the SHSE and SZSE, and $R_{f}$ is China's daily risk-free rate, based on the one-year fixed-term deposit rate or the one-year Treasury note issued by the Chinese government. The construction of the value factor $\left(S M B_{t}\right)$ and the size factor $\left(H M L_{t}\right)$ follows Fama and French (1993); the construction of the momentum factor $\left(U M D_{t}\right)$ follows Carhart (1997). At the end of June each year $t$, the SHSE and SZSE A-shares are sorted into two size groups. The so-called small group includes SHSE and SZSE tradable A-shares whose June total market value (including both tradable and non-tradable shares) is below the median total market value for SHSE and SZSE A-shares and the big group includes stocks with total market capitalization above the median. The SHSE and SZSE A-shares are also allocated to three book-to-price $(B / P)$ equity groups: growth (in the bottom $30 \%$ of the $B / P$ ratios of the SHSE and SZSE A-shares), neutral (in the middle $40 \%$ of the $B / P$ ratios of the SHSE and SZSE A-shares), and value (in the top $30 \%$ of $B / P$ ratios of the SHSE and SZSE A-shares). The $B / P$ ratio of A-shares for June of year $t$ is the book value of equity per share in year $t-1$, divided by the year-end closing price of the A-shares in year $t-1$. The intersection of the size and value sorts creates six VW portfolios, which are refreshed at the end of June each year during the sample period. The market values of all tradable A-shares are used to calculate the VW daily returns. The size factor return, $S M B_{t}$, is the daily difference between the simple average of returns on the three small stock portfolios $(S / L, S / M$, and $S / H)$ and the simple average of the returns on the three big stock portfolios $(B / L, B / M$, and $B / H)$. The value factor return, $H M L_{t}$, is the daily difference between the simple average of returns on the two value portfolios $(S / H$ and $B / H)$ and the simple average of returns on the two growth portfolios $(S / L$ and $B / L)$. The momentum factor return, $U M D_{t}$, is constructed like $H M L_{t}$, except that it is sorted on past returns instead of $B / P$, and the momentum factor sort is updated monthly instead of annually. At the end of each month $t-1$, the SHSE and SZSE Ashares are sorted into three momentum portfolios (low, medium, and high) based on the 30th and 70th percentiles of the SHSE and SZSE A-shares in the past 11 months of cumulative returns to the end of month $t-2$. The intersection of the size sort for the most recent June and the (independent) momentum sort creates six VW portfolios, which are updated monthly. The momentum factor return, $U M D_{t}$, is the simple average of the day $t$ return on the two high-momentum portfolios minus that on the two lowmomentum portfolios. Panel B is the same as Panel A, except that the explanatory variable is monthly returns. 


\begin{tabular}{lcccccc}
\hline Variable & $R m k t$ & $R f$ & $R m k t-R f$ & $S M B$ & $H M L$ & $U M D$ \\
\hline \multicolumn{7}{c}{ Panel A: Monthly Explanatory Returns } \\
\hline $\begin{array}{l}\text { Mean (\%) } \\
\begin{array}{l}\text { St. Dev. } \\
\text { (\%) }\end{array}\end{array}$ & 1.24 & 0.23 & 1.02 & 0.86 & 0.14 & 0.12 \\
$\begin{array}{l}\text { Skewness } \\
\text { t-Value }\end{array}$ & -0.36 & 0.05 & 9.37 & 4.68 & 3.08 & 3.63 \\
\hline & 1.46 & 47.47 & 1.19 & 2.01 & 0.50 & 0.35 \\
\hline $\begin{array}{l}\text { Mean (\%) } \\
\begin{array}{l}\text { St. Dev. } \\
(\%)\end{array}\end{array}$ & 0.06 & 0.01 & 0.05 & 0.04 & 0.01 & 0.01 \\
Skewness & 1.85 & 0.00 & 1.84 & 0.77 & 0.57 & 0.71 \\
$t$-Value & -0.31 & 0.68 & -0.32 & -0.78 & 0.08 & -0.16 \\
\hline
\end{tabular}


Table 4 Turn-of-quarter market-adjusted fund returns

This table reports the market-adjusted returns of Chinese actively managed domestic equity funds around each quarter-end. In Panel A, we calculate the daily market-adjusted returns as the daily net returns of the VW portfolio of Chinese actively managed domestic equity funds minus the daily VW returns of the Chinese stock market, including all tradable A-shares listed on the SHSE and SZSE. The results of the EW fund portfolio are reported in Panel B. The variable Ret End is the average of the funds' market-adjusted returns on the final two trading days of the quarter, whereas Ret Beginning is the average of the market-adjusted returns on the first two trading days of the following quarter. We calculate Ret Beginning net of Ret End at the turn of each quarter as Ret Difference. The averages of Ret End, Ret Beginning, and Ret Difference across all the quarters are also reported. The maximum number of China's active equity mutual funds in this study is 276 . The market-adjusted returns are reported in basis points. The sample period is January 2, 2004, through December 31, 2013. The $t$ statistics of Ret Difference are reported in parentheses.

\begin{tabular}{|c|c|c|c|c|}
\hline \multicolumn{5}{|c|}{ Panel A: VW Market-Adjusted Returns } \\
\hline Quarter & Ret End & Ret Beginning & Difference & $t$-Value \\
\hline$Q 1$ & 21.13 & -6.46 & -27.59 & $(-1.17)$ \\
\hline$Q 2$ & 18.62 & 9.94 & -8.68 & $(-0.24)$ \\
\hline$Q 3$ & 0.29 & -21.40 & -21.69 & $(-0.91)$ \\
\hline$Q 4$ & 16.80 & -54.75 & $-71.55^{* * *}$ & $(-3.83)$ \\
\hline Average & 14.21 & -18.17 & $-32.38 * *$ & $(-2.38)$ \\
\hline \multicolumn{5}{|c|}{ Panel B: EW Market-Adjusted Returns } \\
\hline Quarter & Ret End & Ret Beginning & Difference & $t$-Value \\
\hline$Q 1$ & 15.55 & -13.07 & -28.62 & $(-1.01)$ \\
\hline$Q 2$ & 37.07 & 8.50 & -28.57 & $(-0.92)$ \\
\hline$Q 3$ & -2.95 & -22.81 & -19.86 & $(-0.75)$ \\
\hline$Q 4$ & 17.13 & -48.32 & $-65.45^{* * *}$ & $(-4.18)$ \\
\hline Average & 16.70 & -18.93 & $-35.63 * * *$ & $(-2.87)$ \\
\hline
\end{tabular}


Table 5 Model-based abnormal returns of the portfolio of equity funds around the month-end

This table reports the fund portfolio performance based on Carhart's (1997) four-factor model. The dependent variable $X_{m f, t}$ in each regression is the daily market-adjusted returns and the Carhart (1997) four-factor model is based on the daily abnormal returns of the VW portfolio of Chinese actively managed domestic equity funds. We calculate the daily market-adjusted returns as the daily net returns of the fund portfolio minus the daily VW returns of the Chinese stock market, including all tradable Ashares listed in the SHSE and SZSE. For each mutual fund in the sample, we also calculate its daily abnormal returns, which are the residuals for the Carhart (1997) four-factor version of regression estimated on the fund's daily net returns. The sample includes open-end equity funds in China that hold more than $80 \%$ in the domestic stock market and that were made public at least one year before the end of the sample period. Qualified domestic institutional investor funds, index funds, and exchange-traded funds are excluded. The maximum number of mutual funds in this study is 276 . The regression specification is as below:

$$
X_{m f, t}=a_{0}+a_{1} Y E N D_{t}+a_{2} Y B E G_{t}+a_{3} Q E N D_{t}+a_{4} Q B E G_{t}+a_{5} M E N D_{t}+a_{6} M B E G_{t}+\varepsilon_{m f, t}
$$

The dependent variable $X_{m f, t}$ is regressed on the following binary indicator variables: $Y E N D_{t}$ is one when $t$ is the final two trading days of December; $Y B E G_{t}$ is one when $t$ is the first two trading days of January; $Q E N D_{t}$ is one when $t$ is the final two trading days of March, June, or September; $Q B E G_{t}$ is one when $t$ is the first two trading days of April, July, or October; $M E N D_{t}$ is one when $t$ is the final two trading days of any other month but not the last of a quarter; and $M B E G_{t}$ is one when $t$ is the first two trading days of any other month but not the first of a quarter. The returns are reported in basis points. Each regression has 2,424 daily return observations from January 2, 2004, to December 31,2013 . The $t$-statistics are reported in parentheses. $* * *, * *$, and $*$ represent the $1 \%, 5 \%$, and $10 \%$ levels of significance, respectively. Panel B: Same as Panel A, except that the indicator variables represent a five-day window around the period end. 


\begin{tabular}{|c|c|c|c|c|c|c|}
\hline \multicolumn{7}{|c|}{ Panel A: Two-Day (Before/After) Window } \\
\hline & a1 & $\mathrm{a} 2$ & a3 & a4 & a5 & a6 \\
\hline \multicolumn{7}{|c|}{ Market adjusted } \\
\hline Coefficient & $17.60 * *$ & $-52.40 * * *$ & $24.60 * *$ & -3.63 & 8.63 & -6.17 \\
\hline$t$-Value & $(2.23)$ & $(-3.52)$ & $(2.57)$ & $(-0.35)$ & $(1.44)$ & $(-1.09)$ \\
\hline \multicolumn{7}{|l|}{ Carhart } \\
\hline Coefficient & $9.66 * * *$ & -8.46 & $6.43 *$ & 8.66 & 3.55 & 4.02 \\
\hline$t$-Value & $(2.88)$ & $(-0.84)$ & $(1.85)$ & $(1.56)$ & $(0.94)$ & $(1.28)$ \\
\hline \multicolumn{7}{|c|}{ Panel B: Five-Day (Before/After) Window } \\
\hline \multicolumn{7}{|c|}{ Market adjusted } \\
\hline Coefficient & 3.33 & $-33.40 * * *$ & $13.60 * *$ & -4.20 & 3.50 & $-9.50 * *$ \\
\hline$t$-Value & $(0.55)$ & $(-3.69)$ & $(2.02)$ & $(-0.68)$ & $(0.79)$ & $(-2.39)$ \\
\hline \multicolumn{7}{|l|}{ Carhart } \\
\hline Coefficient & 1.17 & -4.89 & 0.87 & 3.67 & 1.46 & -0.20 \\
\hline$t$-Value & $(0.24)$ & $(-0.85)$ & $(0.29)$ & (1.12) & $(0.55)$ & $(-0.08)$ \\
\hline
\end{tabular}


Table 6 Market-adjusted and abnormal returns of the fund portfolios around the period end

The model is

$$
\begin{aligned}
& X_{m f, t}=a_{0}+a_{1} Y E N D_{t}+a_{2} Y B E G_{t}+a_{3} Q_{1} E N D_{t}+a_{4} Q_{1} B E G_{t}+a_{5} Q_{2} E N D_{t}+a_{6} Q_{2} B E G_{t}+ \\
& a_{7} Q_{3} E N D_{t}+a_{8} Q_{3} B E G_{t}+a_{9} M E N D_{t}+a_{10} M B E G_{t}+\varepsilon_{m f, t} .
\end{aligned}
$$

The dependent variable $X_{m f, t}$ in each regression is the daily market-adjusted returns and Carhart (1997) model-based daily abnormal returns of the VW portfolio of Chinese actively managed domestic equity funds. We calculate the daily market-adjusted returns as the daily net returns of the fund portfolio minus the daily VW returns of the Chinese stock market. For each mutual fund in the sample, we also calculate its daily abnormal returns, which are the residuals for the Carhart (1997) four-factor version of the regression estimated on the fund's daily net returns. The dependent variable $X_{m f, t}$ is regressed on 10 binary indicator variables: $Y E N D_{t}$ is one if $t$ is the final two trading days of December; $Y B E G_{t}$ is one if $t$ is the first two trading days of January; $Q_{1} E N D_{t}$ is one if $t$ is the final two trading days of March; $Q_{1} B E G_{t}$ is one if $t$ is the first two trading days of April; $Q_{2} E N D_{t}$ is one if $t$ is the final two trading days of June; $Q_{2} B E G_{t}$ is one if $t$ is the first two trading days of July; $Q_{3} E N D_{t}$ is one if $t$ is the final two trading days of September; $Q_{3} B E G_{t}$ is one if $t$ is the first two trading days of October; $M E N D_{t}$ is one if $t$ is the final two trading days of any other month but not the last of a quarter; and $M B E G_{t}$ is one if $t$ is the first two trading days of any other month but not the first of a quarter. The term $A L L-Q E N D$ (the average of $Y E N D_{t}, Q_{1} E N D_{t}, Q_{2} E N D_{t}$, and $Q_{3} E N D_{t}$ ) is the final two trading days of each quarter; $A L L-Q B E G$ (the average of $Y B E G_{t}, Q_{1} B E G_{t}, Q_{2} B E G_{t}$. and $\left.Q_{3} B E G_{t}\right)$ is the first two trading days of each quarter. For the five-day window results, the indicator variables are extended to five days instead of two days around each period end. The coefficients are arranged into panels: $Y E N D / Y B E G$ in Panel A, $Q 1 E N D / Q 1 B E G$ in Panel B, Q2END/Q2BEG in Panel C, $Q 3 E N D / Q 3 B E G$ in Panel D, and $(A L L-Q E N D) /(A L L-Q B E G)$ in Panel E. The results are reported in basis points. Each regression has 2,424 daily return observations from January 2, 2004, to December $31,2013 . * * *, * *$, and $*$ represent the $1 \%, 5 \%$, and $10 \%$ significance levels, respectively. 


\begin{tabular}{|c|c|c|}
\hline & Market Adjusted & Carhart \\
\hline \multicolumn{3}{|c|}{ Panel A: Turn of the Year } \\
\hline \multicolumn{3}{|c|}{$Y E N D / Y B E G$ Coefficients } \\
\hline Two-day window $(-2,+2)$ & $18 * * /-52 * * *$ & $10 * * * /-8$ \\
\hline Five-day window $(-5,+5)$ & $3 /-33 * * *$ & $1 /-5$ \\
\hline \multicolumn{3}{|c|}{ Panel B: Turn of Quarter I } \\
\hline \multicolumn{3}{|c|}{$Q 1 E N D / Q 1 B E G$ Coefficients } \\
\hline Two-day window $(-2,+2)$ & $24 /-4$ & $-1 / 8$ \\
\hline Five-day window $(-5,+5)$ & $10 /-10$ & $1 / 3$ \\
\hline \multicolumn{3}{|c|}{ Panel C: Turn of Quarter II } \\
\hline \multicolumn{3}{|c|}{$Q 2 E N D / Q 2 B E G$ Coefficients } \\
\hline Two-day window $(-2,+2)$ & $46^{* *} / 12$ & $5 / 14$ \\
\hline Five-day window $(-5,+5)$ & $21 / 1$ & $2 / 5$ \\
\hline \multicolumn{3}{|c|}{ Panel D: Turn of Quarter III } \\
\hline \multicolumn{3}{|c|}{$Q 3 E N D / Q 3 B E G$ Coefficients } \\
\hline Two-day window $(-2,+2)$ & $4 /-19$ & $15 * * * / 4$ \\
\hline Five-day window $(-5,+5)$ & $9 /-3$ & $-1 / 3$ \\
\hline \multicolumn{3}{|c|}{ Panel E: Turn-of-Quarter Average } \\
\hline \multicolumn{3}{|c|}{$(A L L-Q E N D) /(A L L-Q B E G)$ Coefficients } \\
\hline Two-day window $(-2,+2)$ & $23 * * * /-15 *$ & $7 * * * / 5$ \\
\hline Five-day window $(-5,+5)$ & $11 * * /-11 * *$ & $1 / 2$ \\
\hline
\end{tabular}


Table 7 Fund returns on year-to-date returns around the month-end

The regression is as below:

$X_{m f, t}=a_{0}+a_{1} Y E N D_{t}+a_{2} Y B E G_{t}+a_{3} Q E N D_{t}+a_{4} Q B E G_{t}+a_{5} M E N D_{t}+a_{6} M B E G_{t}+\varepsilon_{m f, t}$.

For each trading day $t$ from January 4, 2005, to December 31,2013, we sort Chinese actively managed domestic equity funds into quintile portfolios based on their total returns over the prior 243 trading days ending day $t-2$. Funds with the lowest year-to-date returns are assigned to quintile 1 and funds with the highest are assigned to quintile 5. The dependent variable $X_{m f, t}$ in each regression is the daily market-adjusted returns and the model-based daily abnormal returns of each portfolio. We calculate the daily market-adjusted returns as the daily net returns of the fund portfolio minus the daily VW returns of the Chinese stock market. For each mutual fund in the sample, we also calculate its daily abnormal returns, which are the residuals for the Carhart (1997) four-factor versions of the regression estimated on the fund's daily net returns. The difference test, P5 - P3 (P1 - P3), is calculated as the quintile 5 (quintile 1) portfolio returns minus the quintile 3 portfolio returns. The number of mutual funds in this study is 276 . The dependent variable $X_{m f, t}$ is regressed on the six dummy variables: $Y E N D_{t}$ is one if $t$ is the final two trading days of December; $Y B E G_{t}$ is one if $t$ is the first two trading days of January; $Q E N D_{t}$ is one if $t$ is the final two trading days of March, June, or September; $Q B E G_{t}$ is one if $t$ is the first two trading days of April, July, or October; $M E N D_{t}$ is one if $t$ is the final two trading days of any other month but not the last of a quarter; and $M B E G_{t}$ is one if $t$ is the first two trading days of any other month but not the first of a quarter. The coefficients are arranged as panels: $Y E N D / Y B E G$ in Panel A, $Q E N D / Q B E G$ in Panel B, and MEND/MBEG in Panel C. The results are reported in basis points. ***, $* *$, and * represent the $1 \%, 5 \%$, and $10 \%$ levels of significance, respectively. 


\begin{tabular}{|c|c|c|}
\hline Portfolio & Market Adjusted & Carhart \\
\hline \multicolumn{3}{|c|}{ Panel A: Turn of the Year } \\
\hline \multicolumn{3}{|c|}{ YEND/YBEG Coefficients } \\
\hline P1 (Loser) & $23 * * * /-63 * * *$ & $19 * * * /-17 *$ \\
\hline $\mathrm{P} 2$ & $8 /-59 * * *$ & $5 /-18^{*}$ \\
\hline $\mathrm{P} 3$ & $6 /-43 * *$ & $3 /-1$ \\
\hline P4 & $17 * * /-54 * * *$ & $11 * * * /-10$ \\
\hline P5 (Winner) & $14 /-40 * *$ & $11 * * / 1$ \\
\hline P1 - P3 & $17 * /-20 * *$ & $16 * /-15$ \\
\hline P5 - P3 & $7 / 4$ & $8 / 3$ \\
\hline \multicolumn{3}{|c|}{ Panel B: Turn of Calendar Quarters } \\
\hline \multicolumn{3}{|c|}{$Q E N D / Q B E G$ Coefficients } \\
\hline P1 (Loser) & $33 * * * / 9$ & $16 * * * / 19 * * *$ \\
\hline $\mathrm{P} 2$ & $25 * * * /-6$ & $9 * * / 5$ \\
\hline P3 & $18 /-5$ & $1 / 5$ \\
\hline $\mathrm{P} 4$ & $24 * * / 12$ & $6 / 21 *$ \\
\hline P5 (Winner) & $26 * * /-1$ & $11^{* * / 6}$ \\
\hline P1 - P3 & $16^{* *} / 15^{*}$ & $16^{* * * / 14 * *}$ \\
\hline P5 - P3 & $8 / 4$ & $10 * / 1$ \\
\hline \multicolumn{3}{|c|}{ Panel C: Turn of Months Instead of Quarter-Ends } \\
\hline \multicolumn{3}{|c|}{$M N E D / M B E G$ Coefficients } \\
\hline P1 (Loser) & $16^{* * /-1}$ & $8 / 7$ \\
\hline $\mathrm{P} 2$ & $13 * /-8$ & $6 / 2$ \\
\hline $\mathrm{P} 3$ & $8 /-6$ & $1 / 5$ \\
\hline P4 & $10 /-7$ & $5 / 4$ \\
\hline P5 (Winner) & $5 /-9$ & $1 / 3$ \\
\hline $\mathrm{P} 1$ - P3 & $8^{* * / 5}$ & $6 / 2$ \\
\hline P5 - P3 & $-3 /-3$ & $1 /-2$ \\
\hline
\end{tabular}


Table 8 Abnormal equity returns around the month-end

In June and December of each year, we rank all stocks held by Chinese active mutual funds based on their ownership ratio into five quintiles (P1 to P5). The institutional ownership ratio is calculated as the share price for each security times the number of shares held by the mutual fund, divided by the security's total market value. The VW average of these stock returns in quintile $\mathrm{P}$ is $X_{q, t}$. The variable $M k t_{t}$ represents the daily VW returns of the Chinese stock market, including all tradable A-shares listed in the SHSE and SZSE. For each quintile, we run the regression

$X_{q, t}=a_{0} M k t_{t}+a_{1} Y E N D_{t}+a_{2} Y B E G_{t}+a_{3} Q E N D_{t}+a_{4} Q B E G_{t}+a_{5} M E N D_{t}+$ $a_{6} M B E G_{t}+\varepsilon_{q, t}$,

where $Y E N D_{t}$ is one when $t$ is the final two working days of December; $Y B E G_{t}$ is one when $t$ is the first two working days of January; $Q E N D_{t}$ is one when $t$ is the final two working days of March, June, or September; $Q B E G_{t}$ is one when $t$ is the first two working days of April, July, or October; $M E N D_{t}$ is one when $t$ is the final two working days of any other month but not the last of a quarter; and $M B E G_{t}$ is one when $t$ is the first two working days of any other month but not the first of a quarter. The returns are reported in basis points. The $t$-statistics are reported in parentheses. $* * *, * *$, and $*$ represent the $1 \%, 5 \%$, and $10 \%$ levels of significance, respectively.

\begin{tabular}{lcccccc}
\hline \multirow{2}{*}{ Portfolio } & \multicolumn{7}{c}{ Coefficient } \\
\cline { 2 - 7 } & YEND & YBEG & QEND & QBEG & MEND & MBEG \\
\hline P1 (low) & -30.40 & 0.35 & $-22.60^{*}$ & -10.90 & $-20.70^{*}$ & -11.50 \\
& $(-1.41)$ & $(0.01)$ & $(-1.75)$ & $(-0.71)$ & $(-1.85)$ & $(-0.97)$ \\
P2 & -16.50 & 3.43 & -14.10 & 10.50 & $-16.80^{*}$ & -8.25 \\
& $(-0.81)$ & $(0.13)$ & $(-1.10)$ & $(0.75)$ & $(-1.98)$ & $(-0.86)$ \\
P3 & -17.60 & 5.01 & -8.41 & 9.08 & -9.69 & -6.01 \\
& $(-1.05)$ & $(0.22)$ & $(-0.79)$ & $(0.73)$ & $(-1.25)$ & $(-0.75)$ \\
P4 & 4.18 & -9.61 & 8.08 & 9.03 & -2.50 & -0.15 \\
& $(0.29)$ & $(-0.54)$ & $(0.74)$ & $(0.73)$ & $(-0.41)$ & $(-0.02)$ \\
P5 (high) & $30.10 * *$ & -14.30 & $15.30^{* *}$ & 15.60 & 8.78 & 2.79 \\
& $(2.29)$ & $(-0.80)$ & $(2.07)$ & $(1.56)$ & $(1.24)$ & $(0.54)$ \\
\hline
\end{tabular}


Table 9 Model-based abnormal returns of the portfolio of closed-end funds around month-end

This table reports the NAV inflation pattern for Chinese closed-end funds around month-ends. The dependent variable $X_{m f, t}$ in each regression is the daily market-adjusted returns and the Carhart (1997) four-factor model-based daily abnormal returns of the VW portfolio of the Chinese closed-end funds:

$$
X_{m f, t}=a_{0}+a_{1} Y E N D_{t}+a_{2} Y B E G_{t}+a_{3} Q E N D_{t}+a_{4} Q B E G_{t}+a_{5} M E N D_{t}+a_{6} M B E G_{t}+\varepsilon_{m f, t}
$$

The dependent variable $X_{m f, t}$ is regressed on the following binary indicator variables: $Y E N D_{t}$ is one when $t$ is the last two trading days of December; $Y B E G_{t}$ is one when $t$ is the first two trading days of January; $Q E N D_{t}$ is one when $t$ is the final two trading days of March, June, or September; $Q B E G_{t}$ is one when $t$ is the first two trading days of April, July, or October; $M E N D_{t}$ is one when $t$ is the final two trading days of any other month but not the last of a quarter; and $M B E G_{t}$ is one when $t$ is the first two trading days of any other month but not the first of a quarter. The returns are shown in basis points. The number of Chinese closed-end funds is 88 . Each regression has 1489 daily return observations ranging from January 2, 2004, to December 31, 2013. The $t$-statistics are shown in parentheses. $* * *, * *$, and $*$ denote the $1 \%, 5 \%$, and $10 \%$ levels of significance, respectively.

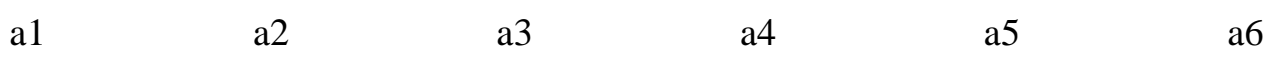

\begin{tabular}{|c|c|c|c|c|c|c|}
\hline \multicolumn{7}{|l|}{$\begin{array}{l}\text { Market } \\
\text { adjusted }\end{array}$} \\
\hline Coefficient & $92.60 * *$ & 65.90 & 46.40 & -9.10 & 10.30 & 24.80 \\
\hline$t$-Value & $(2.41)$ & $(1.07)$ & $(1.62)$ & $(-0.31)$ & $(0.60)$ & $(1.41)$ \\
\hline \multicolumn{7}{|l|}{ Carhart } \\
\hline Coefficient & $5.38^{*}$ & -95.40 & $7.50 * *$ & 0.12 & 1.81 & 5.32 \\
\hline$t$-Value & $(1.76)$ & $(-1.22)$ & $(2.38)$ & $(0.03)$ & $(0.79)$ & $(1.32)$ \\
\hline
\end{tabular}




\section{Appendix A}

\section{Institutional Background}

In comparison with well-developed markets, the mutual fund industry in China has a shorter history. The first closed-end funds and mutual funds in China were established in March 1998 and September 2001, respectively. Although the sector is growing rapidly, the number of funds available on the market is far fewer than the 3,490 funds in the US market (e.g., Brown et al., 2017). ${ }^{30}$ The mutual fund industry in China has expanded in recent years, but its scale is far smaller than that of the US market (which was more than $\$ 10$ trillion in 2013 and thus has great growth potential to meet investor demands. ${ }^{31}$ Despite China's weak legal and financial systems, its economy is one of the fastest growing in the world (Allen et al., 2005). The AUM are expected to increase to 24 trillion yuan by 2020, at which point China will become the second-largest fund management market, following Japan, in Asian markets, indicating enormous opportunities for both Chinese and foreign mutual fund managers. ${ }^{32}$

\footnotetext{
30 See the Investment Company Institute Yearbook at ici.org.

31 See the Investment Company Institute Yearbook at ici.org.

32 See the 2014 report on the Chinese mutual fund market by the consulting firm Oliver Wyman at http://www.oliverwyman.com/content/dam/oliver-wyman/global/en/files/insights/financialservices/2014/WebsiteUpdates/Asset_Management_In_China_English_916.pdf.
} 


\section{Appendix B}

\section{Disclosure Requirements of Fund Portfolio Holdings in China}

The CSRC issued Securities Investment Fund Information Disclosure in July 2004. In addition to semiannual and annual reports, fund managers are required to file quarterly reports in the first and third fiscal quarters, within 15 days of the quarter-ends. The quarterly report should also include, for example, the combination of fund assets, the stock portfolio by industry, the bond portfolio classified by bond types, and the details of the top 10 stocks and top five bonds in fund portfolios according to the proportion of the market value of the NAV. Distinct from the disclosure information required by the quarterly report, fund managers must disclose in the semiannual and annual reports their complete portfolio holdings for the second and fourth fiscal quarters, with a delay up to 60 days and 90 days following the quarter-ends, respectively. Moreover, a fund should include significant changes in equity portfolio holdings during the report period in the semiannual and annual reports. 